\title{
El estudio del periodismo taurino: revisión y actualización bibliográfica
}

\section{The Study of Bullfighting Journalism: Literature Review}

\author{
M. ${ }^{a}$ Verónica de Haro de San Mateo. Universidad de Murcia
}

Recibido: 18-I-2011 - Aceptado: 9-VII-2011

Resumen:

Este artículo pone de relieve aquellos trabajos que han focalizado su atención en el estudio del periodismo taurino con el objetivo de ofrecer un estado de la cuestión de las investigaciones existentes en la materia. El resultado de nuestro estudio, que ha consistido fundamentalmente en la revisión bibliográfica, nos ha permitido de un lado, ofrecer un catálogo de títulos útil para futuros investigadores y de otro, señalar posibles vías de estudio, una vez constatada la ausencia de literatura sobre algunos aspectos relevantes que, sin duda, contribuirían a ampliar, contextualizar y en algunos casos también profundizar, las investigaciones actuales.

Palabras clave:

Periodismo taurino, historia del periodismo, crónica taurina.

\section{Abstract:}

This article highlights those works that have focused on the study of the journalism of bullfighting with the aim of providing a state of the art on current research done on this field. The result of our work, which has mainly consisted on a literature review, has enabled us to develop a portfolio of titles useful for future researchers on one hand, and, besides, to identify possible areas of study, once the lack of investigations on some relevant aspects that would undoubtedly contribute to enlarge, contextualize and, in some cases, deepen current research, has been detected.

Keywords:

Bullfighting Journalism, History of Journalism, Taurine Chronicle. 


\section{Introducción}

La Tauromaquia está íntimamente unida a la Historia de España al menos desde el siglo XVI. Por esta razón, desde los orígenes de la información impresa en nuestro país, las fiestas de toros tienen en ella una presencia considerable. El paulatino desarrollo de la lidia coincide con la introducción y expansión de la imprenta en la península y parece consolidarse de forma paralela a la incipiente actividad periodística de los siglos XVII y XVIII. Es precisamente en esta última centuria cuando la corrida a pie cobra vigencia y se convierte, junto con el teatro, en el espectáculo preferido de los españoles. Su expansión coincide además, en la segunda mitad del siglo XIX con el desarrollo del ferrocarril - un nuevo medio que permite el traslado de los protagonistas de la Fiesta con mayor rapidez- y con la proliferación de las plazas "de fábrica” en las más importantes ciudades españolas. Por aquellos momentos, la naciente prensa industrial española concede una moderada atención a la corrida que comienza a configurarse como espectáculo de masas y es precisamente en este contexto en el que hay que entender el nacimiento de la indisoluble relación entre la crítica y el público de toros. Sin ánimo de ser exhaustivos, conviene apuntar brevemente cómo la información taurina está presente en el panorama periodístico español de forma constante a lo largo del tiempo desde las primitivas Relaciones que se imprimen en nuestro país a finales del siglo XVI.

La aparición de las publicaciones taurinas especializadas es fruto del afianzamiento de la corrida a pie y la consecuente proyección del torero como héroe popular y literario en el primer tercio del siglo XIX. Pero la Tauromaquia tiene una notoria presencia en los ocasionales, gacetas y periódicos que circulan por el país durante los siglos precedentes. Además, la Fiesta está presente en nuestro periodismo dieciochesco no sólo gracias a las reseñas de los festejos que aparecen en los cotidianos sino también a los artículos rubricados por los ilustrados anti taurinos del momento.

La primera crónica taurina aparecida en la prensa diaria es la firmada por "Un Curioso" y se publica en el Diario de Madrid el veinte de junio de 1793. Con ella se inicia una costumbre que se generaliza a partir de la segunda mitad del siglo XIX y llega a nuestros días. Por su parte, la primera revista especializada ve la luz en Madrid en 1819 con el título Estado que manifiesta las peculiaridades ocurridas en esta corrida aunque hasta mediados de siglo tampoco podemos hablar con propiedad de una prensa especializada regular. Algunos de los nombres más destacados del periodismo tauromáquico de esta época son Antonio Peña y Goñi que escribió en El Imparcial y Mariano de Cavia que hizo lo propio en El Liberal. Los cronistas taurinos adquieren ya cierto protagonismo a finales de siglo y La Lidia es la mejor revista del momento por ofrecer no sólo abundante y documentada información sino también bellas cromolitografías de las ganaderías y los matadores más sobresalientes. Gregorio Corrochano y César Jalón “Clarito” cronistas de $A B C$ y The Kon 
Leche respectivamente, son referentes del periodismo taurino del primer tercio del siglo XX, una época que se conoce como la "Edad de Oro del Toreo"1.

Desde su nacimiento, la radio emite información taurina y retransmite festejos en directo. Prueba de ello es que una de las primeras retransmisiones radiofónicas que se realizan desde el exterior es la de una corrida de toros en la que participa Juan Belmonte y que se celebra en la Plaza Vieja de Madrid el ocho de octubre de 1925 (Garitaonaindía, 1988: 41). Finalizada la guerra civil española, Carlos de Larra “Curro Meloja” hace verdadera información taurina en la radio española con su programa "Tauromaquia. Revista Radiofónico Taurina”. De forma paralela, las crónicas taurinas siguen llenando las páginas de los periódicos y las revistas. En este tiempo nace precisamente una publicación que cubre el toreo de toda una época, El Ruedo (1944-1977). Otra gran revista que alberga información taurina en las décadas de los cuarenta y cincuenta es el semanario Dígame, dirigido por Ricardo García “K-Hito”.

Ya en los sesenta, Antonio Díaz Cañabate ejerce la crítica taurina desde la tribuna de $A B C$ mientras que Rafael Campos de España y Manuel Lozano Sevilla hacen lo propio en Radio Nacional de España y "Curro Fetén” en Radio Intercontinental. Es la época en la que la revolución de Manuel Benítez “El Cordobés” llega a la televisión gracias a las retransmisiones en directo de Matías Prats. Por las mismas fechas, José Luis Carabias comienza a dirigir en Radio Nacional de España un espacio que llega a nuestros días, "Clarín". Paralelamente, en el panorama de la prensa surgen nuevos valores que revolucionan la crítica: Vicente Zabala que sucede a Cañabate en $A B C$; Carlos de Rojas en Informaciones; Alfonso Navalón en Diario 16 o Joaquín Vidal que, tras pasar por Pueblo y La Codorniz, comienza a sentar cátedra en El País. La muerte de Franco y el período de tiempo que cubre la transición a la democracia coinciden con una etapa de crisis para la Fiesta. En 1977 desaparece una de las publicaciones taurinas más importantes de todos los tiempos, $E l$ Ruedo, pero un año antes surge en Valencia Aplausos, la revista decana de cuantas se editan sobre el mundo de los toros en la actualidad.

El periodismo taurino en la prensa diaria tiene, a comienzos de los noventa, una calidad informativa y una presencia considerables. A los críticos citados se unen Javier Villán e Ignacio Álvarez “Barquerito” en $E l$ Mundo y Diario 16 respectivamente. Entre la prensa de provincias encontramos abundantes ejemplos de cabeceras que cubren informativamente la temporada más allá de la actualidad derivada de sus propias regiones como El Correo de Andalucía, La Tribuna de Salamanca o La Verdad de Murcia. En radio sobresalen

El primer tercio del siglo XX se ha denominado en la Historia de la Tauromaquia “Edad de Oro del Toreo" por ser el momento en el que coinciden y rivalizan en los ruedos dos de los toreros más importantes: José Gómez Ortega “Gallito” y Juan Belmonte, dos toreros de estilos tan dispares como complementarios que consiguieron concitar el fervor de los públicos y la crítica. 
los programas taurinos “Clarín” de Radio Nacional de España, "El Albero” de COPE y “Los Toros” de Cadena SER. En cuanto a la televisión, el ente público retransmite abundantes festejos y mantiene el programa de actualidad semanal “Tendido Cero” dirigido por Fernando Fernández Román. Para las cadenas autonómicas y privadas, la Fiesta es objeto de gran interés en los años centrales de la década. Un ejemplo de ello son las retransmisiones de Telemadrid, Antena 3 o Canal Plus lideradas por Miguel Ángel Moncholi, Matías Prats y Manuel Molés respectivamente.

En el ámbito de la prensa especializada, a comienzos de los noventa nace la revista 6TOROS6, una publicación que ha interpretado la evolución del toreo en las dos últimas décadas consolidándose como un referente obligado de esta especialidad. Por último, a finales de siglo aparecen algunas páginas con vocación de informar sobre el mundo de los toros en Internet que son sin duda las precursoras de los actuales portales taurinos que han revolucionado la manera de informar sobre la Fiesta en la Red en el siglo XXI, www.burladero.com y www.mundotoro.com.

En la actualidad, las publicaciones taurinas especializadas son un referente obligado para comprender la evolución de la Tauromaquia porque ofrecen una información contextualizada en oposición a la fragmentaria atención que la prensa diaria dedica a la Fiesta. Aplausos -recientemente relanzada por José Luis Benlloch-y 6TOROS6 -dirigida por José Carlos Arévalo- son las únicas revistas españolas editadas con carácter comercial que acuden semanalmente a su cita con el lector para ofrecer la realidad del mundo de los toros con todo lujo de detalles. Además, Tierras Taurinas ${ }^{2}$ y Cuadernos de Tauromaquia ${ }^{3}$ profundizan en el estudio de la Fiesta bimestral y trimestralmente para reflexionar en torno a la evolución del toreo de nuestros días, estudiar las distintas tauromaquias y analizar a fondo la importancia ecológica del toro bravo. No obstante, la información y las crónicas recogidas en los periódicos son un factor del que no puede prescindirse para estar informado del momento actual de la lidia. En este sentido, es obligado repasar las páginas de $A B C$ o El Mundo para leer las piezas periodísticas rubricadas por Andrés Amorós o Zabala de la Serna, entre otros.

La información taurina también está presente en la radio a través de los boletines y los espacios de entretenimiento aunque fundamentalmente gracias a los programas específicos dedicados al mundo de los toros. A “Clarín” -el histórico espacio de RNE que ahora se emite en Radio 5 bajo la dirección de Enrique Mazas y

2 Tierras Taurinas es la versión española de Terres Taurines, una publicación francesa de gran calidad dirigida por André Viard, quien, además de haber sido matador de toros o empresario taurino, es uno de los críticos más reconocidos del país galo y presidente del $O b$ servatoire National des Cultures Taurines.

3 Es la última de las publicaciones taurinas especializadas que ha visto la luz en nuestro país, concretamente en 2008 y está dirigida por José Luis Moreno y Álvaro Acevedo. 
Teo Sánchez- hay que sumar, por ejemplo, el espacio taurino que Manolo Molés conduce en la Cadena SER durante la madrugada de los lunes o el que Juan Ramón Romero presenta en Canal Sur Radio ${ }^{4}$.

A diferencia de lo que ocurre en el medio radiofónico, donde la información taurina es regular y está presente en todas las grandes cadenas ${ }^{5}$, la Tauromaquia es la cenicienta de la televisión de nuestros días. De entre las cadenas privadas, solo Canal Plus sigue ofreciendo a sus abonados una extraordinaria cobertura de las principales ferias ${ }^{6}$ ya que el resto solo se acerca a la Fiesta muy puntualmente y ha dejado de retransmitir festejos. Tampoco lo hace $\mathrm{TVE}^{7}$ aunque la televisión pública sigue manteniendo en la parrilla de La 2 el programa semanal "Tendido Cero" al que nos hemos referido anteriormente y que ahora dirige Federico Arnás. En cambio, las cadenas autonómicas sí retransmiten un buen número de espectáculos taurinos cada temporada y ofrecen amplia y variada información del mundo de los toros a través de programas especializados. "Al Quite” de Canal Nou -dirigido por José Luis Benlloch-, "Al Natural” de 7 Región de Murcia -conducido por José Francisco Bayona- o “Tiempo de Toros” de Castilla La Mancha Televisión -presentado por José Miguel Martín de Blas-, son algunos de los espacios más destacados.

En líneas generales, la atención que los medios de comunicación han dedicado al mundo de los toros ha estado condicionada no sólo por las lógicas e inexorables limitaciones de espacio y tiempo innatas a los soportes informativos tradicionales sino también por las políticas ideológicas de cada empresa informativa. Es innegable que existen numerosas circunstancias culturales, sociales y hasta políticas que son desfavorables a esta manifestación cultural tan original como española y también lo es que la Tauromaquia compite

4 “Carrusel Taurino", el programa taurino de Canal Sur Radio, amplía su horario durante los meses de mayor actividad taurina en España para ofrecer en directo el resultado de los festejos que se celebran simultáneamente en las distintas plazas de toros españolas cada domingo.

5 Precisamente cuando nos disponemos a cerrar este artículo se hace pública la noticia de la desaparición de “El Albero”, el veterano programa taurino que en la Cadena COPE puso en marcha Pedro Javier Cáceres y que ha sido dirigido en las últimas tres temporadas por el presidente de la Unión de Bibliófilos Taurinos, Rafael Cabrera Bonet.

6 El equipo de retransmisiones taurinas de Canal Plus que dirige Manuel Molés ha sido distinguido con el Premio Ondas en la categoría de Televisión en la 57ª edición de estos prestigiosos galardones nacionales en 2010. El jurado de dichos galardones valoró para la concesión de dicho reconocimiento las emisiones en 3D de los partidos de fútbol y las corridas de toros dentro de la categoría Premios Ondas Nacionales de Televisión.

7 TVE dejó de retransmitir festejos taurinos en 2006. En el Manual de Estilo de RTVE, presentado en diciembre de 2010 por el presidente de la corporación, Alberto Oliart, ante la Comisión de Control de RTVE, se incluye a los toros en la sección "violencia con animales" dentro del apartado explícitamente titulado "cuestiones sensibles". No obstante, el manual señala que "RTVE no es indiferente a la relevancia que tiene el mundo de la Tauromaquia ni a su influencia en muchos aspectos socioculturales”, por lo que apuesta por reflejar la "actualidad" del mundo taurino en la programación tanto de la televisión como de la radio, aunque no se emitan corridas. Para ello, dicho manual apuesta por programas específicos dedicados a la Tauromaquia en TVE y RNE y por facilitar "el seguimiento en la programación de aspectos artísticos, literarios, medioambientales y sociales relacionados con el toro de lidia y la Tauromaquia”. 
como espectáculo con otros muchos. Pero no es menos cierto que, a pesar de los numerosos intentos de prohibición que ha sufrido a lo largo del tiempo y que se han intensificado en los últimos años, la Fiesta ha llegado al siglo XXI sin perder un ápice de su esencia conservando además un notable espacio en los medios de comunicación de nuestro país. Quizá por esta razón, el estudio del periodismo taurino ha experimentado un considerable auge en los últimos años gracias a las aportaciones de un buen número de investigadores que han centrado su atención, por citar algunos ejemplos, en la idiosincrasia de la crónica taurina, la historia de sobresalientes publicaciones especializadas o los cambios que Internet ha introducido en el proceso de elaboración y transmisión de la información derivada del mundo de los toros.

El objetivo de nuestro artículo es poner de relieve aquellos trabajos que han focalizado su atención en el estudio de esta especialidad periodística para ofrecer un estado de la cuestión de las investigaciones existentes en la materia.

\section{El estudio de la Historia del Periodismo taurino}

\subsection{En España}

A pesar de que la información taurina está presente en la prensa española desde sus orígenes, entre las obras de carácter general dedicadas a la historia del periodismo en nuestro país, el argumento que nos ocupa se cita, lamentablemente en la mayor parte de los casos, muy de pasada. La excepción la constituyen las obras de Gómez Aparicio (1971) y Alejandro Pizarroso (1992a) en las que el periodismo taurino es protagonista de sendos epígrafes. María Cruz Seoane y Ma Dolores Sáiz, en su tercer tomo de la Historia del periodismo en España (1996), le dedican mayor atención que en las obras anteriores (Seoane, 1983) y posteriores (Sáiz \& Seoane, 2007) pues en cada uno de los períodos considerados y dentro del apartado brindado a las revistas de espectáculos, aparece siempre un espacio titulado “Toros".

Si las obras sobre la Historia del Periodismo español se ocupan modestamente del estudio del periodismo taurino, tampoco lo han hecho en profundidad algunos de los trabajos más relevantes sobre la Historia del Toreo pues aunque en la mayor parte de los casos son frecuentes las referencias a las crónicas y los revisteros taurinos, ninguna de ellas se ha detenido a estudiar el fenómeno de la prensa taurina de cada época. Los trabajos de Néstor Luján (1954), Fernando Gómez de Bedoya (1989) o Fernando Claramunt (1989) son buen ejemplo de ello. Únicamente José Ma Moreiro (1994) se entretiene en considerar el fenómeno de la prensa taurina en unas pocas páginas de su obra Historia, cultura y memoria del arte de torear. En este punto también es interesante resaltar la obra titulada La lidia y el toreo: la historia taurina a través de la prensa de 
quien durante dos décadas fue crítico taurino de "La Hoja del Lunes" de Bilbao y también presidente de la Federación de Asociaciones de la Prensa de España (FAPE), Antonio Petit Caro ${ }^{8}$ (1994).

Quizá el estudio más completo que sobre el periodismo taurino se ha realizado hasta la fecha esté incluido en varios tomos de la monumental obra Los Toros de Cossío y en la reedición que de la misma se ha hecho recientemente ${ }^{9}$. Nos referimos concretamente al volumen ocho, titulado genéricamente Literatura y Periodismo en el que se incluyen además dos nuevos artículos que no aparecen en la colección original. Se trata de los titulados "Los toros y el periodismo" de Alejandro Pizarroso (2007a) e "Internet y el planeta de los toros” de Miguel Ángel Moncholi (2007). En la colección primitiva, el tema está presente en un texto titulado "Los toros y el periodismo" (Cossío, 1965). En el sexto volumen, Juan José de Bonifaz (1981) amplía la relación de escritores y periodistas ofrecida por Cossío. Néstor Luján (1982) retoma el tema en el volumen séptimo mientras que Francisco de Cossío y Corral (1996, 1992, 1990 y 1986) realiza una interesante antología bajo el título genérico "La fiesta de toros a través de las crónicas periodísticas" entre los volúmenes octavo y duodécimo.

Ciertamente, no existe ninguna obra que aborde la Historia del Periodismo taurino en su conjunto. Sí existen estudios parciales que analizan el periodismo taurino de una época o período. La información taurina, como ya hemos apuntado, está presente en los orígenes de la prensa en España. Las Relaciones impresas que informan de los más variados acontecimientos en todos los países de Europa, se ocupan también en nuestro país de funciones reales de toros donde, como si de una crónica taurina se tratase, se describen los lances de los caballeros y el boato que adorna al acontecimiento en sí. Francisco Gómez de Quevedo ejerció como

8 Antonio Petit Caro se licenció en Periodismo por la Universidad de Navarra con una tesis titulada: “Aproximación a la Fiesta de toros. El Periodismo como fuente histórica".

9 El título completo de la obra es Los Toros. Tratado técnico e histórico y fue publicada por vez primera en 1943 bajo la dirección de José Ma de Cossío. Más de medio siglo después de su aparición sigue siendo el tratado más extenso y documentado que existe sobre la Tauromaquia. Definida por el crítico taurino Antonio Díaz-Cañabate como «la Biblia del toro», no es propiamente una Tauromaquia, ni una apología, sino un análisis documentado y un recorrido a través de la historia, los personajes, los cosos, los reglamentos, la técnica del toreo, las ganaderías, el vocabulario, la influencia de la lidia en las Artes y las Letras e incluso la historia del pensamiento anti taurino. El proyecto fue una iniciativa de José Ortega y Gasset, que fue quién sugirió a la editorial Espasa Calpe su gestación y propuso a José Ma de Cossío como director. Ortega siguió de cerca la confección de la colección y llegó a afirmar que era la obra más importante que se había escrito sobre una actividad española concreta. En 1977, tras la muerte de Cossío, tomó el relevo Díaz-Cañabate y añadió un quinto tomo. En 1982 Espasa Calpe añadió un séptimo tomo dedicado a la cultura taurina, al que se unieron tres volúmenes de crónicas taurinas, y los tomos 11 (dedicado al toro de lidia) y el 12, a modo de apéndice hasta 1996. Es constantemente reeditada y actualizada, incluyendo versiones resumidas, en fascículos, etc. Su última edición, de abril de 2007, tiene 30 volúmenes, con diez de ellos dedicados al inventario biográfico y otros diez a crónicas taurinas. Esta última edición ha sido lanzada al público mediante venta en quioscos junto con el dominical del periódico El Mundo. 
cronista taurino para describirnos en verso "la Fiesta de toros, con rejones, al príncipe de Gales, en que llovió mucho” en la que Felipe IV intervino personalmente en Madrid alanceando un toro en $1623^{10}$. José $\mathrm{M}^{\mathrm{a}}$ de Cossío (1965) se ocupa de dar cuenta de la importantísima relación existente entre la Fiesta y las Relaciones o publicaciones ocasionales en su monumental obra Los Toros en la que se recogen más de trescientas entradas correspondientes a los siglos XVI, XVII, XVIII y XIX.

La presencia de la Fiesta en las publicaciones periódicas en el siglo XVIII está documentada en sendas obras en las que también se recogen los testimonios de los antitaurinos ilustrados de la época. Rafael Cabrera y Ma Teresa Artigas (1991) han catalogado todas las menciones que a favor o en contra de la Tauromaquia aparecen en la prensa madrileña a lo largo del siglo mientras que Alejandro Pizarroso (2004 y 1990) también reflexiona sobre esta cuestión con cierta amplitud. Las encontradas opiniones que los intelectuales españoles de buena parte del siglo XX mantienen con respecto a la Fiesta en sus ensayos y artículos publicados en prensa también han sido estudiadas por Rosario Cambria (1974).

Celia Forneas (1998b) es autora de un interesante artículo sobre el periodismo taurino de 1898, aunque Alejandro Pizarroso es quizá el investigador que más se ha ocupado de estudiar la historia del periodismo taurino en el conjunto de la historia del periodismo español. A las obras ya citadas cabe añadir sus estudios sobre el periodismo taurino en la época de Antonio Ordóñez (2001), las publicaciones taurinas catalanas (Pizarroso, 1994), valencianas (Pizarroso, 1992b) y madrileñas (Pizarroso 1989) o más recientemente el que resume la trayectoria de los revisteros y cronistas que han cubierto la historia de la Plaza de Toros de Las Ventas, también llamada “catedral del toreo"11" (Pizarroso, 2006).

Con carácter local o regional pero referidos a épocas más recientes cabe citar el artículo de Rafael Cabrera Bonet (2009) dedicado a las publicaciones taurinas catalanas aparecido en Caireles -la única revista de esta especialidad editada en Cataluña en la actualidad bajo la dirección del escritor Fernando del Arco- o los libros de Juan Barceló (1982) y Ma Verónica de Haro (2009a) sobre el periodismo taurino en Murcia, en los que se repasa el modo en el que la información del mundo de los toros ha estado presente en los medios de comunicación de dicha Comunidad Autónoma a lo largo del tiempo y en la actualidad respectivamente.

En lo que concierne a las publicaciones taurinas especializadas es preciso mencionar las más importantes catalogaciones de las mismas. Luis Carmena y Millán (1898) es el autor del primer índice de periódicos taurinos. Su obra es, sin lugar a dudas, la base sobre la que se han construido todas las demás. A la ya citada de

10 El texto completo de esta crónica puede encontrarse en Altabella, J. (1965): Crónicas taurinas, Madrid: Taurus, pp.49-54.

11 A la Plaza de Toros Monumental de Las Ventas del Espíritu Santo, en Madrid, se la denomina “catedral del toreo" por su importancia en el mundo de los toros. 
Cossío (1965) cabe añadir la que se encuentra en el Ensayo de Bibliografía Taurina publicado por la Biblioteca Nacional (1973) que comprende más de mil trescientas entradas y que actualmente se encuentra en fase de actualización a cargo de Fernando García Bravo. También tiene mucho interés el catálogo de la exposición celebrada en la Hemeroteca Nacional de Madrid en 1991 bajo el título "Los toros en la prensa", que mostró parte de la colección del aficionado y bibliófilo Antonio Castillo (1991) ${ }^{12}$.

Siguiendo con los estudios sobre las publicaciones especializadas es preciso resaltar algunos estudios monográficos dedicados a algunas de las cabeceras más importantes de la historia del periodismo taurino. Pedro Romero de Solís ha trazado la trayectoria del Boletín de Loterías y de Toros (Romero de Solís, 1996) y de Taurología (Romero de Solís, 2000) paradigmas de las publicaciones culturales exclusivamente dedicadas a la Fiesta editadas en España. Se trata de dos extensos y bien documentados artículos que han sido publicados en la Revista de Estudios Taurinos -editada por la Fundación de Estudios Taurinos y con el patrocinio de la Real Maestranza de Caballería de Sevilla- la única publicación académica que tiene a la Fiesta como protagonista. Ma Verónica de Haro (2004) también se ha ocupado de analizar la última citada revista para detenerse en el estudio de sus páginas publicitarias pues se trata de la única cabecera especializada en el mundo de los toros que se ha nutrido de publicidad ajena al mundo taurino. Otro trabajo digno de resaltar es el que Luis Nieto (1986) consagra a la revista La Lidia, aunque más que una historia de la publicación en sí en el contexto del periodismo de la época es un repaso -a través de los textos publicados- del público y de los otros protagonistas de la Tauromaquia en el tiempo de la citada revista.

En vías de publicación se encuentran dos trabajos más, fruto de sendas tesis doctorales dirigidas por Alejandro Pizarroso: la que José Luis Ramón (2009) brinda a El Ruedo y la que Ma Verónica de Haro (2009c) dedica a 6TOROS6. Ambas investigaciones mantienen una estructura similar y contemplan el estudio de la trayectoria y filosofía de estas revistas así como su relación con la historia del periodismo español y el mundo taurino contemporáneos a ellas. Por su parte, el análisis de El Ruedo contempla la vida de la publicación desde su nacimiento como suplemento taurino del diario deportivo Marca en 1944 hasta su desaparición en los años de la transición a la democracia en nuestro país y una de sus virtudes es que logra describir cómo los cambios de propiedad y dirección afectan a la política editorial de la revista taurina más importante de la segunda mitad del siglo XX. Respecto al estudio sobre 6TOROS6, esta investigación desvela cómo

12 La obra es interesante por contener, además del catálogo citado, una serie de artículos relacionados con el periodismo taurino como los titulados "La noticia de toros. Viaje a sus orígenes” de Diego Ruiz Morales; “Los precedentes de la prensa taurina especializada” de Rafael Cabrera o "El Enano. Breve historia de un periódico taurino” del propio Castillo. 
algunos de los hitos de esta publicación que acaba de cumplir sus primeros veinte años de vida lo son también del conjunto de la historia del periodismo español. Entre ellos están el ser la primera revista taurina que se edita, durante un tiempo, también en francés o ser la pionera en intentar una edición internacional para México, aunque quizá el más importante es haber logrado ser la primera publicación de este género capaz de ofrecer la crónica y las imágenes de los festejos más relevantes celebrados en cualquier parte del mundo hasta el domingo inmediatamente anterior a su venta, gracias a la pronta incorporación de las nuevas tecnologías y a su idea de universalidad.

Por continuar con las investigaciones que llevaron a sus autores a alcanzar el grado de doctor cabe citar la de Miguel Ángel Moncholi (2004) sobre las retransmisiones taurinas de la cadena autonómica Telemadrid entre los años 1992 y 1996. Ciertamente, los estudios que versan sobre la idiosincrasia de la información taurina en los medios audiovisuales y su influencia en la audiencia son casi inexistentes. Esta circunstancia resulta paradójica si se tiene en cuenta que las retransmisiones televisivas de las corridas de toros han marcado un punto de inflexión en la consideración de la Fiesta por parte de los públicos.

Para finalizar este apartado no queremos olvidarnos de las investigaciones que han focalizado su atención en la idiosincrasia de la información taurina en Internet y en los cambios que ha propiciado este nuevo soporte en la prensa especializada en el mundo de los toros. Al trabajo ya citado que ha sido incluido en la reedición de Los Toros de Cossío (Moncholi, 2007) y a la obra que narra la experiencia del primer portal taurino en la Red -www.burladero.com- coordinada por el mismo autor (Moncholi, 2003) hay que añadir los artículos publicados por Alejandro Pizarroso y Ma Verónica de Haro (2003 y 2002) o los que ha realizado la última autora en solitario más recientemente (De Haro, 2009b y 2006). En líneas generales, estos trabajos ponen de relieve cómo la llegada de Internet ha propiciado un enriquecimiento sustancioso en la parcela de la información taurina.

\subsection{En otros países en los que se vive la Fiesta}

La Fiesta no es patrimonio exclusivo de España. En la actualidad tiene vigencia en otros países europeos como Francia y Portugal y al otro lado del Atlántico se vive con pasión en Colombia, Ecuador, Perú, Venezuela y México aunque, sin lugar a dudas, de entre todos los citados, México es el segundo de los países en donde la Tauromaquia tiene más importancia. Al igual que sucede con la historia del periodismo taurino en nuestro país, lamentablemente tampoco existe una historia del periodismo taurino en Latinoamérica. Resulta curioso que una especialidad periodística tan arraigada en los países citados, no haya merecido más atención por parte de los investigadores de la comunicación. 
Pese a todo, existen algunas obras de gran interés. El periodismo taurino en México (García Bolio, 1991) es quizá, la obra más significativa de la disciplina que nos entretiene ya que ofrece al lector un excelente panorama de la evolución del periodismo taurino y una completa lista de todas las publicaciones taurinas editadas en ese país. Del mismo autor es una muy recomendable recopilación bibliográfica de la tauromaquia mexicana (García Bolio, 1989). También destaca la Historia del Toreo en México de Nicolás Rangel (1980) porque además de evocar la evolución de la Fiesta en el México colonial, ofrece abundantes referencias de las Relaciones de temática taurina publicadas en la República, cuestión que también aborda unos años después José Francisco Coello Ugalde (1988). Igualmente, en México se han publicado recopilaciones de algunos números de importantes publicaciones taurinas. García Bolio (1980) ha propiciado la de la revista Gazeta de México y a su celo también se debe la reedición casi completa de $L a$ Banderilla (García Bolio, 1994). Para finalizar este repaso a los estudios sobre el periodismo taurino en México queremos hacer mención al trabajo titulado El periodismo digital en México. Una aproximación a su realidad taurina en Internet defendido en el XI Congreso Nacional de Periodismo Digital celebrado en Huesca (De Haro, 2010).

Alberto Lopera “Loperita" (1989) nos presenta el periodismo taurino de su país en un capítulo de su interesante obra titulada Colombia, tierra de toros, un libro en el que se destaca el nombre de los principales cronistas taurinos de las más importantes ciudades taurinas colombianas.

Por su parte, Auguste Lafront y Marc Thorel son los autores que se han ocupado del estudio del periodismo taurino francés. El primero, en su espléndida Bibliographie de la presse taurine française, recoge fichas de todas las publicaciones taurinas francesas editadas hasta la fecha de aparición de la obra, clasificadas por año de nacimiento, junto a un interesante listado alfabético de apodos de los principales periodistas taurinos galos (Lafront, 1995). Del mismo autor es también la recopilación de testimonios sobre la Fiesta de los viajeros extranjeros a su paso por España durante los siglos XVI al XVIII (Lafront, 1988). Thorel (1983) nos presenta el periodismo taurino francés en Le Toreo Illustré, Toros et journalisme. Un ancétre de la presse taurine, una obra lujosamente editada por la Unión de Bibliófilos Taurinos de Francia. Aunque no es un estudio sobre el periodismo taurino sino más bien una recopilación de textos publicados en prensa, no queremos olvidar la antología publicada por Massoutier (1956). En lo que respecta a Portugal no hemos encontrado referencias sobre estudios específicos sobre prensa taurina pero sí tenemos noticia de una obra que recoge la presencia del mundo taurino en la literatura lusa (Tavares, 1966). 


\section{El estudio de la crónica taurina}

No se puede negar que "desde el punto de vista del periodismo especializado existe también el periodismo taurino" (Pizarroso, 1999: 277) entendido éste, en líneas generales, como todo aquel testimonio en forma de noticia, reportaje, crónica, entrevista o artículo de opinión que tiene como protagonista a la Fiesta de los Toros en cualquier soporte informativo -prensa, radio, televisión e Internet-. Los profesores Manuel Bernal, Ma Celia Forneas, Olga Pérez y Juan Carlos Gil son quienes han estudiado la idiosincrasia y la evolución de la crónica taurina -el género más característico de esta especialidad periodística- en mayor profundidad.

Existe una obra muy interesante en la que se recogen las intervenciones de los participantes en el seminario dedicado al estudio de la crónica taurina celebrado en Sevilla en 1998 bajo la coordinación de Manuel Bernal, Carmen Espejo y Ma del Mar García (1998). Este libro tiene la virtud de compilar no sólo el testimonio de investigadores expertos en la materia sino también el de algunos críticos taurinos. Por esta razón, la obra aporta una perspectiva teórica y práctica del género híbrido por excelencia del periodismo taurino. También es digno de mención el artículo de Alberto Hernando García-Cervigón (2006) sobre la lengua en la crónica taurina. Por su parte, María Celia Forneas es la investigadora que más ha ahondado, sin duda, en el estudio de la naturaleza y la evolución de la crónica taurina. Su libro La crónica taurina actual, un texto literario y de opinión (Forneas, 1998a) y los artículos publicados en la revista Estudios sobre el Mensaje Periodístico (Forneas, 2007, 2006 y 2001b) son un referente en este aspecto. Bajo su dirección, Olga Pérez Arroyo (1998) realizó una tesis doctoral -la primera sobre el periodismo taurino defendida en una universidad española- sobre las crónicas de Gregorio Corrochano, otro de los grandes maestros del periodismo taurino en nuestro país. De la misma autora son los libros Manual de la crónica taurina (Pérez Arroyo, 2002) y ¿Cómo escribir crónicas taurinas? (Pérez Arroyo, 2003) en los que se abordan las características principales de este género informativo y de opinión desde una perspectiva muy divulgativa. También bajo la dirección de la profesora Forneas, Ma Almudena Hernández (2009) ha defendido recientemente una tesis doctoral sobre las crónicas de Vicente Zabala y Joaquín Vidal a propósito de las actuaciones de José Miguel Arroyo "Joselito" en la madrileña Plaza de Toros de Las Ventas con el objetivo de constatar la presencia del ethos retórico de los mencionados críticos en sus respectivas producciones periodísticas.

Sería de gran interés estudiar la obra autobiográfica de la crítica pero lamentablemente pocos periodistas la han cultivado. Existe, no obstante, alguna excepción. Nos referimos a las Memorias de César Jalón "Clarito” (1972), una obra clave para entender no sólo la trayectoria de este autor sino también el periodismo taurino de toda una época y el toreo contemporáneo a ella. César Jalón Aragón fue miembro del Partido Republicano Radical y ocupó la cartera de Ministro de Comunicaciones en los gobiernos que, durante la II 
República, presidió Alejandro Lerroux. Pero este paso por la política no puede considerarse más que anecdótico en la larga vida de César Jalón ya que donde realmente destacó y por lo que es recordado es por su faceta de crítico taurino. Firmó sus crónicas bajo el seudónimo de "Clarito" en los periódicos Liberal e Informaciones siendo uno de los referentes principales de la Tauromaquia durante los años cincuenta del siglo XX. Otra obra autobiográfica similar es la de Antonio Reyes “Don Criterio" (1932) en la que el cronista plasma su trayectoria como revistero en El Liberal de Sevilla.

Abundan por el contrario los estudios dedicados a la obra y trayectoria de conocidos críticos. Un ejemplo de ello son los trabajos que la profesora Celia Forneas consagra a Santos López Pelegrín "Abenamar" a quien se atribuye la Tauromaquia de Francisco Montes "Paquiro"13 (Forneas, 1999) o a Serafín Estébanez Calderón "El Solitario”, el célebre autor de las famosas Escenas Andaluzas (Forneas, 2000). Por su parte, Ignacio de Cossío ha estudiado la biografía de José María de Cossío quien, además de ser el iniciador de la enciclopedia taurina más importante, fue gran investigador y crítico literario, miembro de la Real Academia y presidente del Ateneo de Madrid entre otras muchas actividades (Cossío Pérez de Mendoza, 1999).

Dirigida por el profesor Bernal, Juan Carlos Gil ha realizado una tesis doctoral sobre la obra periodística taurina del escritor madrileño costumbrista más significativo del siglo XX, Antonio Díaz Cañabate (Gil González, 2006), parte de la cual ha sido publicada bajo el título Evolución histórica y cultural de la crónica taurina: de las primitivas reseñas a la crónica impresionista (Gil González, 2007). Sobre el mismo autor, también ha trabajado Ignacio de Cossío (2004) con el objetivo de poner de relieve la trayectoria del periodista que llegó a ser una de las principales firmas de El Ruedo y $A B C$ y que también se encargó de continuar la ardua tarea emprendida por José $\mathrm{M}^{\text {a }}$ de Cossío en su monumental obra Los Toros. Esta enciclopedia taurina no habría llegado a editarse sin el impulso capital de José Ortega y Gasset de quien acaban de publicarse recientemente algunos textos inéditos sobre la Fiesta, seleccionados por Felipe González Alcázar y Ma Isabel Ferreiro Lavedán (Ortega y Gasset, 2010)

Al hilo de lo que comentamos, queremos destacar las biografías de Ignacio Sánchez Mejías escritas por algunos autores porque en ellas se subraya la faceta periodística del malogrado torero sevillano. Es el caso de las publicadas por Andrés Amorós (1998) o Antonio García Ramos y Francisco Narbona (1988). También son muy interesantes las recopilaciones que han efectuado Alfonso Carlos Sáiz Valdivieso (Sánchez Mejías, 1991) o más recientemente Juan Carlos Gil (Sánchez Mejías, 2010) de los textos rubricados por el matador

13 Francisco Montes "Paquiro" fue discípulo del célebre Pedro Romero en la Escuela de Tauromaquia de Sevilla. Con su nombre apareció en el año 1836 la célebre Tauromaquia, obra del crítico taurino Santos López Pelegrín, “Abenamar”, la más importante preceptiva taurina de todos los tiempos o. 
que motivó el universalmente famoso "Llanto" de Federico García Lorca. Ciertamente, Sánchez Mejías es una de las figuras más apasionantes de la historia del toreo. Escritor, autor y promotor teatral, conductor de coches de carreras y piloto de aviación, actor, jugador de fútbol y de polo, presidente del Real Betis Balompié y de la Cruz Roja en Sevilla, el torero sevillano también cultivó el ejercicio del periodismo con manifiesta virtud tal como puede comprobarse en la última obra citada. En ella se ponen de relieve las crónicas de viajes y las crónicas taurinas que Sánchez Mejías rubricó en el diario sevillano La Unión durante 1925 así como sus artículos sobre la censura periodística, publicados cuatro años más tarde en el popular vespertino $E l H e$ raldo de Madrid. Este libro - que tiene la virtud de compilar toda la producción periodística de Sánchez Mejías- incluye algunas entrevistas y textos de otros autores así como el texto de la famosa conferencia impartida por el torero en la Universidad de Nueva York (que muestra algunas variaciones sobre la versión que ya se conocía) además de una amplia introducción de Juan Carlos Gil que ayuda a contextualizar la producción periodística así como a profundizar en la complejidad de esta figura del toreo y de la sociedad y la cultura españolas del primer tercio del siglo XX.

También resultan de interés las compilaciones de crónicas aparecidas en algunas publicaciones periódicas. De entre las editadas, queremos resaltar especialmente la que recoge los trabajos aparecidos en el Memorial literario de Madrid entre 1784 y 1788 porque contribuye a contextualizar la relación entre los toros y el periodismo del siglo XVIII (Unión de Bibliófilos Taurinos, 1956) y la que compila algunos artículos taurinos aparecidos en El Semanario Pintoresco Español de Mesonero Romanos por ejemplificar cómo las referencias a la Tauromaquia también están presentes en el periodismo denominado "costumbrista" (López Rinconada, 1995 y UBT, 1963). Más reciente es la recopilación efectuada por Ignacio Ruiz Quintano que se ha materializado en Las Taurinas de ABC, un libro que ha sido editado al cuidado de Catalina Luca de Tena y prologado por Vicente Zabala de la Serna. La obra se enmarca en el conjunto de actos conmemorativos del centenario de un periódico que se ha caracterizado a lo largo de su historia por su firme y decidido apoyo a la Fiesta y recoge algunas de las más famosas crónicas rubricadas por Agustín de Foxá, Julio Camba, Gregorio Corrochano, Antonio Díaz Cañabate o Vicente Zabala en esta cabecera a lo largo de su trayectoria (VV.AA., 2003).

\section{Otros estudios relacionados con el periodismo taurino}

No queríamos terminar este estado de la cuestión de los estudios relativos al periodismo taurino sin al menos mencionar algunos otros trabajos afines a él. Parece claro el vínculo del humorismo gráfico con la prensa pues éste siempre se ha expresado a través de publicaciones periódicas. En la especialidad que 
nos ocupa, es pertinente destacar el estudio de José Luis Dávila (1992) titulado "El humorismo gráfico en los toros" presente en la monumental obra de Cossío; la Taubromaquia de Fernando Corella (1996) que recoge la práctica totalidad de las viñetas taurinas que el autor publicó posteriormente en la revista 6 TOROS6 así como el libro que Fernando del Arco de Izco (2004) dedica a Fernando Vinyes por su faceta como caricaturista.

Aunque por sí misma es autosuficiente, la fotografía taurina constituye una parte muy importante de las publicaciones taurinas especializadas e incluso ha cobrado cierto protagonismo en la prensa diaria como acompañamiento de las crónicas a lo largo de los años. Sobre la historia de la fotografía taurina hay una obra casi definitiva de Manuel Durán y Juan Miguel Sánchez Vigil (1991) editada lujosamente por Espasa.

En cambio, la información taurina transmitida a través de imágenes en movimiento no ha merecido un estudio tan enjundioso. Sería interesante indagar en la presencia del mundo de los toros en los noticieros cinematográficos y los programas informativos de radio y televisión pero lamentablemente, tampoco tenemos noticia de que nadie se haya dedicado a este menester. Sí lo han hecho, y con probada virtud, algunos estudiosos que se han esforzado en testimoniar la relación entre el cine y el mundo taurino entre los que cabe destacar a Carlos Fernández Cuenca sobre el cine taurino español (1963) o Ignacio Taibo sobre el cine taurino mexicano (1987).

\section{Propuestas para futuras investigaciones}

El estudio del periodismo taurino resulta ineludible para profundizar en las claves que han propiciado no sólo el perfeccionamiento de la lidia sino también que el mundo de los toros haya evolucionado al hilo de los tiempos. La Tauromaquia en tanto Arte ha conseguido desarrollarse gracias a la interacción de sus protagonistas: el torero, el toro y el público. Pero no podemos olvidarnos del cuarto protagonista -los medios de comunicación- puesto que en ellos se encierra gran parte de la memoria colectiva alcanzable para quienes desde la actualidad quieren bucear en el pasado de la Fiesta y también porque ellos influyen de tal manera en los públicos (y son influidos por éstos) y lógicamente en los toreros y en el toro (es decir, en los ganaderos) que, sin su concurso, no podríamos entender la evolución permanente de la Fiesta.

En los últimos años, el estudio de esta especialidad periodística ha suscitado el interés de algunos investigadores pero, a pesar de ello, el Periodismo Taurino ha sido objeto de un número muy modesto de estudios en relación a su historia y potencial y, aunque existen meritorias investigaciones parciales sobre la cuestión, aún no se ha realizado un estudio monográfico sobre la relación que los medios han tenido con la Fiesta ni 
una Historia del Periodismo Taurino en su conjunto. En este sentido resultaría muy interesante y reveladora una investigación que pusiera de relieve la continuada presencia que el periodismo taurino ha tenido en la historia del periodismo español y en la de todos aquellos países en los que la Fiesta se vive con idéntica pasión.

A pesar de que existen investigaciones académicas sobre algunas de las revistas taurinas más relevantes, también sería deseable que aumentara el número de este tipo de estudios porque son muchas las cabeceras sobre las que sería necesario arrojar luz. De este modo se daría a conocer no sólo la historia, filosofía y trascendencia de dichas publicaciones sino también la trayectoria de quienes las hicieron posible, con lo cual se enriquecería el catálogo de estudios sobre algunos de los más influyentes críticos a lo largo de la historia. De igual modo, sería interesante estudiar la incidencia de la publicidad en la prensa taurina especializada con el fin de analizar el modo en el que los anunciantes han condicionado la política editorial de algunas publicaciones a lo largo del tiempo.

Para continuar con este breve esbozo de los estudios que sería recomendable acometer debemos señalar el interés de aquellos que estuvieran relacionados con la profesionalización del periodista taurino o los concernientes al análisis de la idiosincrasia de la información taurina en función del soporte. La inmensa mayoría de los estudios a los que nos hemos referido en este artículo corresponden a trabajos que han focalizado su atención en la prensa y las publicaciones especializadas. En este sentido, resulta paradójico comprobar cómo las investigaciones sobre la información taurina en los medios audiovisuales son casi inexistentes teniendo en cuenta que las retransmisiones televisivas de las corridas de toros han marcado un punto de inflexión en la consideración de la Fiesta por parte de los públicos. Otro tanto sucede con los estudios sobre la naturaleza de la información taurina radiofónica, donde sería interesante estudiar, entre otros muchos aspectos, las características de las retransmisiones y el fenómeno de las tertulias. También sería significativo el estudio del impacto de los gabinetes de prensa de las figuras del toreo en los medios de comunicación contemporáneos así como el análisis del modo en el que Internet está condicionando el proceso de elaboración y transmisión de la información taurina en los medios.

Tradicionalmente, a falta de estudios reglados, el periodista taurino ha ido dotándose de los conocimientos necesarios para el ejercicio de esta especialidad periodística (los fundamentos de la lidia y las diferentes suertes del toreo; la idiosincrasia del toro bravo y sus diferentes encastes; las particularidades del reglamento taurino, la jerga, etc.) gracias al contacto con las propias fuentes, es decir, los profesionales del entorno taurino: ganaderos y toreros fundamentalmente. Sin embargo, el estudio del periodismo taurino y de su idiosincrasia es una apuesta clara por la mayor y mejor formación de las nuevas generaciones de pe- 
riodistas taurinos. Por ello queremos resaltar las iniciativas universitarias que se han desarrollado en los últimos tiempos en aras de mejorar la formación de quienes ejercen el periodismo especializado en el mundo de los toros.

Durante la última década de la pasada centuria, algunas universidades incluyeron en la programación de sus cursos de verano varios seminarios dedicados a la Tauromaquia en los que el periodismo taurino estuvo muy presente. Hubiera sido interesante que las conferencias que se impartieron en dichos cursos se hubieran recogido en sendas publicaciones porque habrían llegado a un público mucho mayor pero lamentablemente no ha sucedido. Sí hay testimonio de las conferencias que desde el año 2001 coordina Rafael Cabrera Bonet en la Universidad San Pablo CEU de Madrid. Bajo el título Aula de Tauromaquia, al término de cada curso académico se vienen editando las ponencias de cada edición entre las que casi siempre se incluye algún trabajo relacionado con el periodismo taurino.

Además, en algunas facultades la información taurina está contemplada como una especialidad periodística que se referencia y estudia en asignaturas tales como "Periodismo cultural" o "Fundamentos del periodismo especializado" e incluso en la universidad hispalense existe una cátedra dedicada a la Fiesta de los Toros que también se ocupa puntualmente de la información taurina. Ya en el año 1998 nace en la facultad de Ciencias de la Información de la Universidad Complutense de Madrid el primer Curso de Periodismo Taurino con el deseo de formar periodistas especializados. En la actualidad, este curso -patrocinado por la Fundación Taurina de la Comunidad de Madrid “José Miguel Arroyo Joselito” y dirigido por Alejandro Pizarroso y Miguel Ángel Moncholi- tiene una duración de trescientas horas teórico prácticas en las que se ofrece a los alumnos formación sobre la historia de la Tauromaquia, la idiosincrasia de los principales encastes de la ganadería brava, el ritual taurino y naturalmente, las características de la información taurina y su evolución a lo largo de la historia del periodismo español.

Con la intención de poner al alcance de futuros investigadores un catálogo de títulos útil que aliente nuevas investigaciones en la materia, nuestro trabajo alcanza su fin con una bibliografía en la que se recogen las obras citadas en este artículo.

\section{Referencias bibliográficas}

Altabella, J. (1965): Crónicas taurinas. Madrid: Taurus.

Amorós Guardiola, A. (1998): Ignacio Sánchez Mejías. Madrid: Alianza.

Barceló Jiménez, J. (1982): Los toros, el periodismo y la literatura en Murcia. Murcia: Real Academia Alfonso X el Sabio. 
Bagués Navarro, V. “Don Ventura” (1927): Escritores taurinos españoles del siglo XIX. Barcelona.

Bernal Rodríguez, M. \& Espejo Cala, C. \& García Gordillo, Mª M. (eds.) (1998): Actas del seminario -coloquio sobre La Crónica Taurina-I Jornadas de Comunicación en la Real Maestranza de Caballería de Sevilla, celebradas del 4 al 6 de marzo de 1998. Sevilla: Padilla Libros Editores \& Libreros.

Biblioteca Nacional (1973): La Fiesta Nacional (Ensayo de una Bibliografía taurina). Madrid: Artes Gráficas Cavileño.

Cabrera Bonet, R. (2009): “Revistas taurinas publicadas en Barcelona”. Caireles, no 28, pp. 39-44.

Cabrera Bonet, R. y Artigas, Ma T. (1991): Los Toros en la Prensa Madrileña del siglo XVIII. Madrid: Consejería de Cultura.

Cambria, R. (1974): Los toros: Tema polémico en el ensayo español del siglo XX. Madrid: Gredos.

Carmena y Millán, L. (1898): El periodismo taurino. Índice de periódicos taurinos de 1819 a 1898. Madrid.

Castillo, A. (1991): Los toros en la prensa. Revistas de toros, Catálogo de la Exposición de Antonio Castillo celebrada en la Hemeroteca Nacional de Madrid del 15 al 19 de abril de 1991. Madrid: Hemeroteca Nacional.

Claramunt, F. (1989): Historia ilustrada de la Tauromaquia, aproximación a una pasión ibérica. Madrid: Espasa Calpe.

Coello Ugalde, J. F. (1988): Relaciones taurinas en la Nueva España, provincias y extramuros. Las más curiosas e inéditas, 1519-1835. México: Universidad Nacional Autónoma de México.

Corella, F. (1996): La Taubromaquia. Madrid: Egartorre.

Cossío, J. Ma (1965): “Los toros y el periodismo” en Cossío, J. Ma (de): Los Toros, Tratado técnico e histórico, Tomo 2. Madrid: Espasa Calpe, pp.531-559; pp. 560-578; pp.579-587 у 592-680.

Cossío Pérez De Mendoza, Ignacio (2004): El Maestro Cañabate, de los toros y de la vida. Madrid: Tutor.

- (1999): Cossío y los Toros. Madrid: Espasa Calpe.

Cossío y Corral, F. (1996): “La fiesta de toros a través de las crónicas, Cuarta Parte: (1947-1996)”, en Cossío y Corral, F: Los Toros, Tratado técnico e histórico, Tomo XII. Madrid: Espasa Calpe.

- (1992): “La fiesta de los toros a través de las crónicas periodísticas, Tercera parte: (1920-1947)”, en Cossío y Corral, F: Los Toros, Tratado técnico e histórico, Tomo X. Madrid: Espasa Calpe, Madrid.

- (1990): "La fiesta de los toros a través de las crónicas periodísticas, Segunda parte: (1883-1920)”, en Cossío y Corral, F:: Los Toros, Tratado técnico e histórico, Tomo IX. Madrid: Espasa Calpe, Madrid.

- (1986): "La fiesta de los toros a través de las crónicas periodísticas. Primera parte: (1793-1883)", en Cossío y Corral, F: Los Toros, Tratado técnico e histórico, Tomo VIII. Madrid: Espasa Calpe.

Dávila, J. L. (1992): “El humorismo gráfico en los toros” en COSSÍO, Los Toros, Tratado técnico e histórico, Tomo VII. Madrid: Espasa Calpe, pp.499-570. 
De Bonifaz, J. J. (1981): “Enumeración y breves informes de escritores taurinos. Apéndice: periódicos taurinos”, en Cossío, J. Ma \& Díaz Cañabate, A.: Los Toros, Tratado técnico e histórico, Tomo VI. Madrid: Espasa Calpe, pp. 871-1.038.

De Haro De San Mateo, M. ${ }^{a}$ V. (2010): "El periodismo digital en México. Una aproximación a su realidad taurina en Internet”, en Sabés, F. (coord.), Análisis y propuestas en torno al periodismo digital. Huesca: Ayuntamiento de Huesca y Asociación de la Prensa de Aragón, pp. 314-328.

- (2009a): (coord.) La información taurina en los medios de comunicación de la Región de Murcia. Murcia: EDITUM.

- (2009b): “La información taurina cambia de tercio en el ruedo de Internet” en Fernández, P. (coord.): Rompiendo moldes. Discurso, géneros e hibridación en el siglo XXI. Sevilla: Comunicación Social Ediciones y Publicaciones, pp. 50-74.

- (2009c): “6TOROS6, revista de actualidad taurina”, Tesis doctoral. Madrid: Facultad de Ciencias de la Información de la Universidad Complutense de Madrid.

- (2006): “Diez años de información taurina en Internet. Un nuevo modelo de periodismo taurino” en Sabés, F. (coord.): Análisis y propuestas en torno al periodismo digital. Huesca: Ayuntamiento de Huesca y Asociación de la Prensa de Aragón, pp. 214-224.

- (2004): “Taurología, referente de las revistas culturales taurinas”. En Sanz Establés, C., Sotelo González, J. \& Rubio Moraga, Á. L. (coords.): Prensa y Periodismo Especializado II, (historia y realidad actual). Guadalajara: Editores del Henares, pp. 401- 410 .

De Haro De San Mateo, Ma V. y Pizarroso Quintero, A. (2003): “Los Toros en la Red”. En García Baquero, A., Romero De Solís, P. (eds.): Fiestas de Toros y Sociedad. Sevilla: Universidad de Sevilla, pp. 857- 880.

- (2002): “Periodismo y mundo taurino en Internet”. En Fernández Sanz, J. J., Rueda Laffond, J. C. \& Sanz Establés, C. (eds.): Prensa y Periodismo Especializado (historia y realidad actual). Guadalajara: Ayuntamiento de Guadalajara, pp. 653-672.

Del Arco De Izco, F. (2004): Los toros, la caricatura y Fernando Vinyes. Madrid: Egartorre.

Durán Blázquez, M. \& Sánchez Vigil, J. M. (1991): Historia de la fotografía taurina. Madrid: Espasa Calpe, 1991.

Fernández Cuenca, C. (1963): Toros y toreros en la pantalla. San Sebastián.

Forneas Fernández, Ma C. (2007): “Orígenes y evolución de la crónica taurina”, Estudios sobre el mensaje periodístico, nº 13, pp. 385-398.

- (2006): “Una aproximación a la crónica/crítica literaria”, Estudios sobre el mensaje periodístico, no 12, pp. 285-304.

- (2001a): Periodistas taurinos españoles del siglo XIX. Madrid: Fragua.

- (2001b): “La crónica impresionista de Don Modesto”, Estudios sobre el mensaje periodístico, no 7, pp. 337-363.

- (2000): “Serafín Estébanez Calderón, El Solitario”, Estudios sobre el mensaje periodístico, no 6, pp. 167-192. 
- (1999): “Abenamar, periodista taurino”, Revista de Estudios Taurinos, no 10, pp. 91-120.

- (1998a): La crónica taurina actual, Un texto informativo, literario y de opinión. Madrid: Biblioteca Nueva.

- (1998b): “El periodismo taurino de 1898”, Estudios sobre el mensaje periodístico, no 4, Servicio de Publicaciones UCM, Madrid, 1998, pp. 71-86.

García Bolio, S. (ed.) (1994): La Banderilla. México, D.F.

- (1991): El Periodismo Taurino en México. México D.F.

- (1989): Bibliografía mexicana de la tauromaquia. México D.F.

- (ed.) (1980): Gazeta de México (1722, 1728-1742). México: Bibliófilos Taurinos de México.

García Ramos, A. \& Narbona, F. (1988): Ignacio Sánchez Mejías. Madrid: Espasa Calpe.

Garitaonaindía, C. (1988): La radio en España, 1923-1939, de altavoz musical a arma de propaganda. Bilbao: Universidad del País Vasco.

Gil González, J. C. (2007): Evolución histórica y cultural de la crónica taurina: de las primitivas reseñas a la crónica impresionista. Madrid: Editorial Vision Net.

- (2006): “La obra periodística de Antonio Díaz-Cañabate. Desde la crónica impresionista hasta su consolidación como fenómeno mediático". Tesis doctoral. Sevilla: Facultad de Comunicación de la Universidad de Sevilla.

Gómez Aparicio, P. (1971): “Periodismo taurino”, en Aparicio, P.: Historia del periodismo español, t. II, De la Revolución de septiembre al Desastre colonial. Madrid: Editora Nacional, pp. 582-599.

Gómez de Bedoya, F. (1989): Historia del toreo y de las principales ganaderías de España. Madrid: Egartorre.

Hernando García Cervigón, A. (2006): “La lengua en la crónica taurina”, Estudios del mensaje periodístico, pp.349-364.

Hernández Pérez, Ma A. (2009): “José Miguel Arroyo Joselito, análisis de sus actuaciones en la Plaza de Las Ventas: las crónicas de $A B C$ y El País”. Tesis doctoral. Madrid: Facultad de Ciencias de la Información de la Universidad Complutense de Madrid.

Jalón, C. (1972): Memorias de Clarito. Madrid: Guadarrama.

La Cadena y Brualla, R. (1931): Aragoneses que han escrito de toros (prólogo de “Don Ventura”). Zaragoza.

Lafront, A. (1995): Bibliographie de la presse taurine française: 1883-1994. Nimes: Unión de Bibliófilos Taurinos de Francia.

- (1988): Compilation, étude et notes, La fête espagnole des taureaux vue par les voyageurs étrangers (du XVI au XVIII siècle). Nimes : Unión de Bibliófilos Taurinos de Francia.

Lopera, A. (1989): “Cronistas y Medios de Comunicación Taurinos” en Lopera, A.: Colombia Tierra de Toros. Madrid: Espasa Calpe, pp. 304332.

$62 \mid n^{\circ} 13$ | doxa.comunicación 
López de Zuazo Algar, A. (1981): Catálogo de de periodistas españoles del siglo XX. Madrid: Gráficas Chapado.

López Rinconada, M. Á. (1995): La Tauromaquia en el Semanario Pintoresco Español (Madrid, 1836 - 1857). Madrid: Imprenta Coimoff.

Luján, N. (2007): “Toros y Periodismo” en Cossío: Los Toros, Literatura y Periodismo, vol. 8. Madrid: Espasa, pp.609-649.

- (1982): “Los toros y el periodismo” en Cossío: J. Ma \& Díaz Cañabate A.: Los Toros, Tratado técnico e histórico, Tomo 7. Madrid: Espasa Calpe, pp. 301-333.

- (1954): Historia del Toreo. Barcelona: Destino.

Massoutier, R. (1956): Cinquante ans de critique taurine (Pages choisies). Nimes.

Moncholi Chaparro, M. Á. (2007): “Internet y el planeta de los toros”. En Cossío: Los Toros. Literatura y Periodismo, vol. 8, Madrid: Espasa, pp.680-703.

- (2004): “Las retransmisiones taurinas en televisión en la Comunidad de Madrid. (Periodo 1992-1996)”. Tesis doctoral. Madrid: Facultad de Ciencias de la Información de la Universidad Complutense de Madrid.

- (2003): Burladero.com, la aventura de los toros en Internet. Madrid: Egartorre.

Moreiro, J. Ma (1994): Historia, cultura y memoria del arte de torear. Madrid: Alianza.

Nieto Manjón, L. (1986): La Lidia. Modelo de Periodismo. Madrid: Espasa Calpe.

Ortega y Gasset, J. (2010): “Notas de trabajo de la carpeta Toros. Primera parte”, Revista de Estudios Orteguianos, n 21 . Edición de Felipe González Alcázar y M. Isabel Ferreiro Lavedán, pp. 27-58.

Ossorio y Bernard, M. (1903): Ensayo de un catálogo de periodistas españoles del siglo XIX. Madrid: Imprenta y litografía de Juan Palacios.

Pérez Arroyo, O. (2003): ¿Cómo escribir crónicas taurinas?. Madrid: Universidad Camilo José Cela.

- (2002): Manual de la crónica taurina. Madrid: Ediciones Estudio del Arte.

- (1998): “La crónica taurina: Gregorio Corrochano y su época (1914-1920)”. Tesis doctoral. Madrid: Facultad de Ciencias de la Información de la Universidad Complutense de Madrid.

Petit Caro, A. (1994): La lidia y el toreo: la historia taurina a través de la prensa. Madrid: Privanza.

Pizarroso Quintero A. (2007a): “Los toros y el periodismo” en Cossío: Los Toros. Literatura y Periodismo, vol. 8. Madrid: Espasa, pp. 650-679.

- (2007b): “Cátedra del toreo (1996-2007)”. En Cossío: Los Toros. Crónicas (1981-2007), vol. 30. Madrid: Espasa, pp. 271292.

- (2006): "75 años de Las Ventas, tres cuartos de siglo de periodismo taurino. Revisteros y críticos de la plaza de toros de 
Las Ventas", en Abella, C. (coord.): Las Ventas, 75 años de historia. Madrid: Centro de Asuntos Taurinos de la Comunidad de Madrid, pp. 217-235.

- (2004): “Prensa y toros en el siglo XVIII”, Revista de Estudios Taurinos, nº 18, pp. 205-249.

- (2001): “El periodismo taurino en la época de Ordóñez”, en AA.VV.: Antonio Ordóñez y el toreo de su tiempo. Ronda: Real Maestranza de Caballería, pp.2 3-48.

- (1999): “Un caso peculiar de la profesión periodística: el periodismo taurino”. En Barrera, C.: Del gacetero al profesional del periodismo: evolución histórica de los actores humanos del "cuarto poder". Madrid: Fragua, pp. 277-296.

- (1994): "Notas para una historia del periodismo y de las publicaciones taurinas en Cataluña”, Gazeta, no 1, (Monográfico dedicado a las “Actes de les Primeres Jornades d'Història de la Premsa”), pp. 303-314.

- (1992a): “Algo genuinamente español: el periodismo taurino”. En Pizarroso Quintero, A.: De la Gazeta Nueva al canal Plus. Breve historia de los medios de comunicación en España. Madrid: Editorial Complutense, pp. 74-77.

- (1992b): “Notas para el estudio de la prensa y el periodismo taurino valencianos”. En Laguna, A. y López, A. (eds.): Doscents Anys de Premsa Valenciana. Valencia: Generalitat Valenciana, pp. 269-302.

- (1990): “La Fiesta de los Toros y el periodismo español del siglo XVIII", Periodismo e Ilustración en España, Estudios de Historia Social, n 52/53, pp. 369384.

- (1989): “Algunas noticias sobre las publicaciones taurinas madrileñas (1874-1931)”, en Bahamonde Magro, Á. \& Otero Carvajal, L. E. (eds.): La sociedad madrileña durante la Restauración 1876 1931. Madrid: Alfoz, pp. 373-387.

Ramón Carrión, J. L. (2009): “La revista. El Ruedo Treinta y tres años de información taurina en España (1944-1977)”. Tesis doctoral. Madrid: Facultad de Ciencias de la Información de la Universidad Complutense de Madrid.

Rangel, N. (1980): Historia del Toreo en México. Época colonial (1529-1821). México: Cosmos.

Reyes, A. “Don Criterio” (1932): Treinta años de crítica taurina en El Liberal de Sevilla. Prólogo de Juan Belmonte. Sevilla: Tipografía Moderna.

Romero De Solís, P. (2000): “Las revistas culturales de toros en España: Taurología”, Revista de Estudios Taurinos, Homenaje a Taurología, no 12, pp. 173-264.

- (1996): “Boletín de Loterías y de Toros, Córdoba, 1992-1995”, Revista de Estudios Taurinos, no 3, pp. 241-246.

Sáiz, Ma D. y Seoane, M ${ }^{a}$ C. (2007): Cuatro Siglos de Periodismo en España, De los avisos a los periódicos digitales. Madrid: Alianza, 2007.

- (1996): Historia del periodismo en España, 3. El siglo XX: 1898-1936. Madrid: Alianza.

Sánchez Mejías, I. (2010): Sobre Tauromaquia, Obra periodística, conferencias y entrevistas (Edición al cuidado de Juan Car-

64 | n 13 | doxa.comunicación 
los Gil). Córdoba: Berenice.

- (1991) Escritos periodísticos, Edición al cuidado de Alfonso Carlos Sáiz Valdivieso. Bilbao: Laida.

Seoane, Mª C. (1983): Historia del Periodismo en España, 2, el siglo XIX. Madrid: Alianza.

Taibo, F. I. (1987): Los Toros en el Cine Mexicano. México: Instituto Nacional de Bellas Artes.

Tavares Rodrigues, U. (1966): Selecçao e prefacio. O mundo do toureio na literatura de lingua portuguesa. Lisboa.

Thorel, M. (1983): Toros et Journalisme. Un ancêtre de la presse taurine. Béziers, 1893. Le Toreo Illustré. Nimes: Unión de Bibliófilos Taurinos de Francia.

Unión de Bibliófilos Taurinos (1963): Toros y literatura costumbrista, Tres artículos del Semanario Pintoresco Español, (Nota preliminar de Antonio García Ramos). Madrid: Unión de Bibliófilos Taurinos.

- (1956): Los Toros en el Memorial Literario, Instructivo y Curioso de la Corte de Madrid. 1784-1788. (Prólogo de Diego Ruiz Morales). Madrid: Unión de Bibliófilos Taurinos.

VV. AA. (2003): Las Taurinas de ABC. Madrid: Ediciones Luca de Tena. 